\title{
Catalytic (Asymmetric) Methylene Transfer to Aldehydes
}

\author{
Alessandro Piccinini, Sarah A. Kavanagh, Paul B. Connon and \\ Stephen J. Connon*
}

Centre for Synthesis and Chemical Biology, School of Chemistry, University of Dublin, Trinity College, Dublin 2, Ireland

connons@tcd.ie

Received Date (will be automatically inserted after manuscript is accepted)

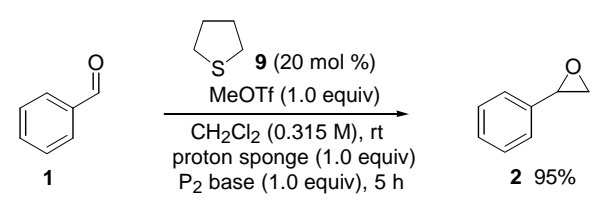

ABSTRACT

An investigation into the poor activity of sulfides as catalysts for sulfonium-ylide-mediated methylene transfer to aldehydes has indicated that ylide formation is the problematic catalytic cycle step. Alkylation with traditional electrophiles does not proceed with sufficient efficiency to allow the sulfide to be used catalytically. Methyl triflate rapidly alkylates cyclic thiolanes under mild conditions, allowing their use in efficient aldehyde epoxidation reactions (in conjunction with phosphazene bases) at loadings as low as 10 mol\%.

Over the past 15 years the Corey-Chaykovsky (CC) epoxidation process ${ }^{1}$ involving the reaction between sulfonium ylides and aldehydes has evolved into a highly synthetically useful, catalytic asymmetric methodology. ${ }^{2}$ The use of semistabilized ylides such as those derived from the reaction of either benzyl halides or $\alpha$ haloesters/amides with chiral sulfides at catalytic loadings can result in excellent levels of product enantiomeric excess. $^{3}$ In stark contrast however, the asymmetric

(a) Johnson A. W.; LaCount, R. B. J. Am. Chem. Soc. 1961, 83, 417. (b) Corey, E. J.; Chaykovsky, M. J. Am. Chem. Soc. 1962, 84, 867. (c) Franzen V.; Driesen, H. -E. Chem. Ber. 1963, 96, 1881. (d) Corey, E. J. Chaykovsky, M. J. Am. Chem. Soc. 1965, 87, 1353.

Recent reviews: (a) Li, A. -H.; Dai, L.-X.; Aggarwal, V. K. Chem. Rev. 1997, 97, 2341. (b) Aggarwal, V. K.; Richardson, J. Chem. Commun. 2003, 2644. (c) Aggarwal, V. K.; Winn, C. L. Acc. Chem. Res. 2004, 37, 611. (d) McGarrigle, E. M.; Myers, E. L.; Illa, O.; Shaw, M. A.; Riches S. L.; Aggarwal, V. K. Chem. Rev. 2007, 107, 5841.

Selected representative examples: (a) Furukawa, N.; Sugihara, Y.; Fujihara, H. J. Org. Chem. 1989, 54, 4222. (b) Aggarwal, V. K.; AbdelRahman, H.; Jones, R. V. H.; Standen, M. C. H. J. Am. Chem. Soc. 1994, 116, 5973. (c) Aggarwal, V. K.; Ford, J. G.; Thompson, A.; Jones, R. V. H.; Standen, M. C. H. J. Am. Chem. Soc. 1996, 118, 7004. (d) Zanardi, J.; Leriverend, C.; Aubert, D.; Julienne, K.; Metzner, P. J. Org. Chem. 2001, 66, 5620. (e) Saito, T.; Akiba, D.; Sakairi, M.; Kanazawa, S. Tetrahedron Lett. 2001, 42, 57. (f) Winn, C. L.; Bellenie, B. R.; Goodman, J. M. Tetrahedron Lett. 2002, 43, 5427. (g) Aggarwal, V. K.; Alonso, E.; Bae, I.; Hynd, G.; Lydon, K. M.; Palmer, M. J.; Patel, M.; Porcelloni, M.; Richardson, J.; Stenson, R. A.; Studley, J. R.; Vasse, J. L. Winn, C. L. J. Am. Chem. Soc. 2003, 125, 10926. (h) Davoust, M.; synthesis of terminal epoxides via methylene transfer is characterized by moderate yields and a requirement for (super)stoichiometric loadings of chiral sulfide catalysts. $^{4,5}$ For example, the benchmark literature procedures (Scheme 1) for the asymmetric sulfonium ylide-mediated formation of styrene oxide (2) from the archetypal substrate benzaldehyde (1) developed independently by Aggarwal ${ }^{6 a, b}$ and Goodman ${ }^{6 c}$ involve the use of 100-200 mol\% of the chiral sulfides 3-4 and produce 2 in ca. $50-60 \%$ yield and $<60 \%$ ee. ${ }^{7}$

Brière, J. -F.; Jaffrès, P. -A.; Metzner, P. J. Org. Chem. 2005, 70, 4166 (i) Deng, X. -M.; Cai, P.; Ye, S.; Sun, X. -L. Liao, W. -W.; Li, K.; Tang, Y.; Wu Y. -D.; Dai, L.-X. J. Am. Chem. Soc. 2006, 128, 9730. (j) Davoust, M.; Cantagrel, F.; Metzner, P.; Brière, J. -F. Org. Biomol. Chem. 2008, 6, 1981. (k) Bi, J.; Aggarwal V. K. Chem. Commun. 2008, 120.

${ }^{4}$ (a) Trost, B. M.; Hammen, R. F. J. Am. Chem. Soc. 1973, 95, 962 (b) Bellenie, B. R.; Goodman J. M. Chem. Commun. 2004, 1076.

${ }^{5}$ Breau, L.; Durst, T. Tetrahedron: Asymmetry 1991, 2, 367.

6 (a) Aggarwal, V. K.; Ali, A.; Coogan M. P. J. Org. Chem. 1997, 62, 8628. (b) Aggarwal, V. K.; Coogan, M. P.; Stenson, R. A.; Jones, R. V. H.; Fieldhouse, R.; Blacker J. Eur. J. Org. Chem. 2002, 319. (c) Bellenie, B. R.; Goodman J. M. Chem. Commun. 2004, 1076.

Hiyama et al. (ref. 7a) claimed that 2 could be synthesized in $97 \%$ $e e$ in the presence of a chiral phase transfer catalyst. However our group (ref. 7b) recently demonstrated that Hiyama was in error and has actually observed the decomposition of the catalyst to a related epoxide (with a relatively large specific rotation) during the formation of $\mathbf{2}$ as a racemate: (a) Hiyama, T.; Mishima, T.; Sawada, H.; Nozaki, H. J. Am. 
Scheme 1: Benchmark literature procedures for the sulfoniumylide mediated methylene transfer to benzaldehyde (1)

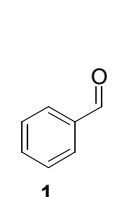

1

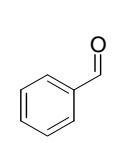

1

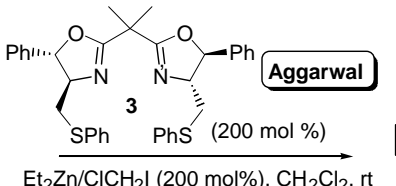

$\mathrm{Et}_{2} \mathrm{Zn} / \mathrm{ClCH}_{2} \mathrm{l}(200 \mathrm{~mol} \%), \mathrm{CH}_{2} \mathrm{Cl}_{2}$, rt $54 \%, 47 \%$ ee

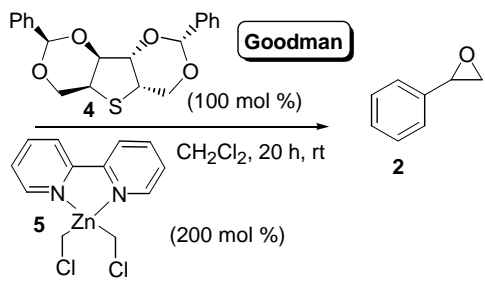

$56 \%, 57 \%$ ee

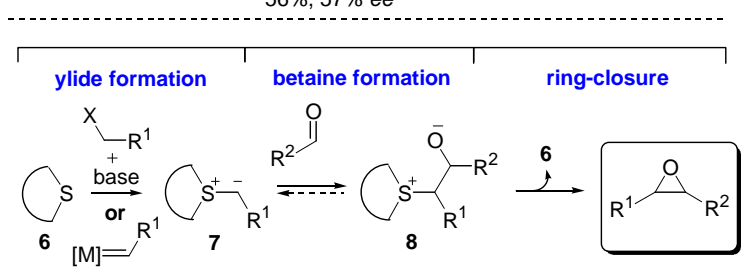

$\mathrm{X}=\mathrm{I}, \mathrm{Br} \quad \mathrm{M}=\mathrm{Rh} \quad \mathrm{R}^{1}=\mathrm{H}$, aryl, COR $\mathrm{R}^{2}=$ alkyl, aryl

While it has been (reasonably) proposed that the moderate levels of stereocontrol observed in these reactions relative to those involving more stabilized ylides are due to irreversible betaine formation in the case of the addition of the methylide to aldehydes, ${ }^{2,8}$ we found the poor levels of catalyst activity (high activity and low sulfide loadings are normal in the corresponding benzylidene transfer reactions for example) difficult to fathom. Given that CC reactions are proposed to occur via betaine intermediates (8, Scheme 1) derived from attack of the ylide $\mathbf{7}$ on the aldehyde, ${ }^{9,10}$ it seemed likely

Chem. Soc. 1975, 97, 1626. (b) Kavanagh, S. A.; Connon, S. J. Tetrahedron: Asymmetry 2008, 19, 1414.

${ }^{8}$ Aggarwal has suggested that stereocontrol in the reaction of (semi)stablized ylides with aldehydes is influenced by the reversibility of betaine formation and a rate-determining $C-C$ bond rotation of the betaine to allow the $\mathrm{S}_{\mathrm{N}} 2$ ring closure to occur (see ref. 9). It is notable however that in silico studies by Goodman (ref. 10) on the enantioselective formation of styrene oxide from a semistabilized ylide derived from $\mathbf{4}$ and benzaldehyde found that the relative energies of the transition states of the intially formed betaines were excellent predictors of experimentally observed product enantioselectivity in the case studied. Thus is cannot be ruled out that enantioselectivity can derive from kinetic control alone (i.e. facial selectivity in the attack of the ylide on the aldehyde) in these reactions, which would make the modest observed enantioselectivites associated with methylene transfer more difficult to explain.

(a) Aggarwal, V. K.; Calamai, S.; Ford, J. G. J. Chem. Soc. Perkin Trans. 1 1997, 593. (b) Aggarwal, V. K.; Harvey, J. N.; Richardson, J. J. Am. Chem. Soc. 2002, 124, 5747. (c) Aggarwal, V. K.; Alonso, E.; Bae, I.; Hynd, G.; Lydon, K. M.; Palmer, M. J.; Patel, M.; Porcelloni, M.; Richardson, J.; Stenson, R. A.; Studley, J. R.; Vasse, J. -L.; Winn, C. L. J. Am. Chem. Soc. 2003, 125, 10926. (d) Aggarwal, V. K.; Richardson, J. J. Chem. Commun. 2003, 2644. (e) Aggarwal V. K.; Charmant, J. P. H.; Fuentes, D.; Harvey, J. N.; Hynd, G.; Ohara, D.; Picoul, W.; Robiette, R.; Smith, C.; Vasse, J. -L.; Winn, C. L. J. Am. Chem. Soc. 2006, 128, 2105. (f) Edwards, D. R.; Montoya-Peleaz, P.; Crudden, C. M. Org. Lett. 2007, 9, 5481. to us that betaine formation from a methylide $\left(7, \mathrm{R}^{1}=\mathrm{H}\right.$, Scheme 1) should be more efficient (if anything) than the corresponding reaction using less nucleophilic (semi)stabilized ylides $\left(7, \mathrm{R}^{1}=\right.$ aryl or COR). This leaves either ring closure of the betaine or the formation of the sulfonium ylide as the factor responsible for the low catalytic activity associated with methylene transfer.

Since it is also difficult to see how sterically unencumbered methylide-derived betaines $\left(\mathbf{8}, \mathrm{R}^{1}=\mathrm{H}\right)$ would fail to ring-close where more substituted (albeit aryl substituted) analogues succeed - we reasoned that inefficient formation of the sulfonium ylide (i.e. $\mathbf{6} \rightarrow \mathbf{7}$, Scheme 1) was the most plausible underlying cause of the observed sluggish catalysis of methylene transfer. This thesis was also supported by Goodman's observation that treatment of $\mathbf{4}$ with MeI followed by base did not lead to the formation of $\mathbf{2}$ from $\mathbf{1}$. ${ }^{\text {c }}$

To test this hypothesis, we initially treated benzaldehyde (1) with the unhindered sulfide 9 (20 $\mathrm{mol} \%$ ) in the presence of stoichiometric amounts of solid $\mathrm{KOH}$ and $\mathrm{MeI}$ in $\mathrm{CH}_{2} \mathrm{Cl}_{2}$ (Scheme 2). Under these conditions we observed the formation of 2 in $18 \%$ yield. A repeat of this experiment using $100 \mathrm{~mol} \%$ of the preformed sulfonium salt $\mathbf{1 0}$ however, resulted in a 90\% yield under otherwise identical conditions (Scheme 2). Thus it is clearly the rate of alkylation to form the sulfonium salt $\mathbf{1 0}$ which is problematic in this process. ${ }^{11}$

Scheme 2: Preliminary experiments: identification of sulfonium salt formation as the problematic step

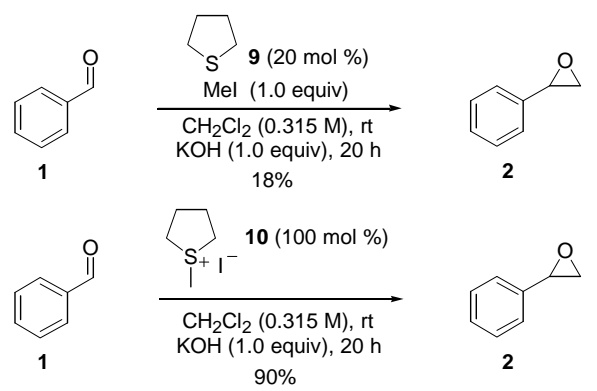

With this in mind we carried out a screening study aimed at the identification of an agent which would methylate the sulfide at a rate conducive to smooth catalysis of the CC reaction under these conditions. The results of these experiments are outlined in Table 1. With the sulfide utilized at the same concentration as that used in the attempted catalytic CC reaction (see Scheme 2) we found that methyl iodide furnished the corresponding iodide salt in 25\% yield after $24 \mathrm{~h}$ (entry 1). Methyl tosylate and methyl mesylate failed to alkyate $\mathbf{9}$ under these conditions (entries 2-3) and even powerful methylating electrophiles such as Meerwein's salt and

\footnotetext{
${ }^{10}$ Silva, M. A.; Bellenie, B. R.; Goodman, J. M. Org. Lett. 2004, 6, 2559.

It is noteworthy that analysis of these reactions by ${ }^{1} \mathrm{H}$ NMR spectroscopy did not indicate the formation of methanol.
} 
dimethylsulfate gave unsatisfactory alkylation rates in dichloromethane solvent (entries 4-5). However, use of commercially available MeOTf resulted in clean, rapid formation of salt $\mathbf{1 0 f}$ inside $15 \mathrm{~min}$ at ambient temperature (entries 6-7). MeOTf could be conveniently added to the reaction via syringe and could be also used in acetonitrile solvent; however its high reactivity renders it incompatible with THF (entries 8-9).

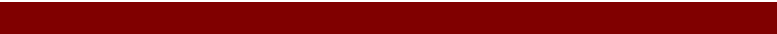

Table 1. Identification of a suitable alkylating agent

\begin{tabular}{|c|c|c|c|c|c|}
\hline entry & alkylating agent & product & solvent & $\begin{array}{l}\text { time } \\
\text { (h) }\end{array}$ & $\begin{array}{l}\text { yield } \\
(\%)^{\mathrm{a}}\end{array}$ \\
\hline 1 & MeI & $10 a$ & $\mathrm{CH}_{2} \mathrm{Cl}_{2}$ & 24 & 25 \\
\hline 2 & MeOTs & $10 \mathrm{~b}$ & $\mathrm{CH}_{2} \mathrm{Cl}_{2}$ & 24 & 0 \\
\hline 3 & MeOMs & 10c & $\mathrm{CH}_{2} \mathrm{Cl}_{2}$ & 24 & 0 \\
\hline 4 & $\mathrm{Me}_{3} \mathrm{O}^{+} \mathrm{BF}_{4}^{-}$ & 10d & $\mathrm{CH}_{2} \mathrm{Cl}_{2}$ & 24 & 36 \\
\hline 5 & $\mathrm{Me}_{2} \mathrm{SO}_{4}$ & $10 \mathrm{e}$ & $\mathrm{CH}_{2} \mathrm{Cl}_{2}$ & 24 & 33 \\
\hline 6 & MeOTf & $10 f$ & $\mathrm{CH}_{2} \mathrm{Cl}_{2}$ & 24 & 100 \\
\hline 7 & MeOTf & $10 f$ & $\mathrm{CH}_{2} \mathrm{Cl}_{2}$ & 0.25 & 100 \\
\hline 8 & MeOTf & $10 f$ & $\mathrm{MeCN}$ & 0.25 & 100 \\
\hline 9 & MeOTf & $10 f$ & THF & 24 & 0 \\
\hline
\end{tabular}

${ }^{\text {a }}$ Determined by ${ }^{1} \mathrm{H}$ NMR spectroscopy using an internal standard.

With catalytically promising alkylation conditions in hand, we next required an appropriate base. Table 2 details the results of a screening study to identify an active and easily handled base which would transform triflate salt $\mathbf{1 0 f}$ into $\mathbf{2}$ in the presence of $\mathbf{1}$ in dichloromethane solvent.

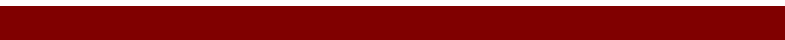

Table 2. Identification of a suitable base

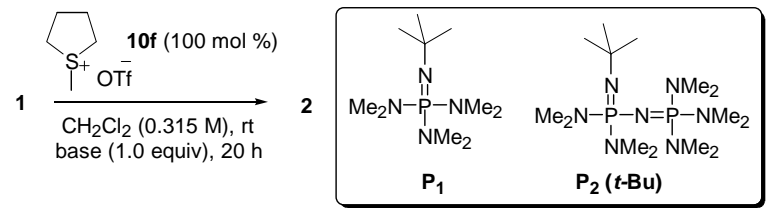

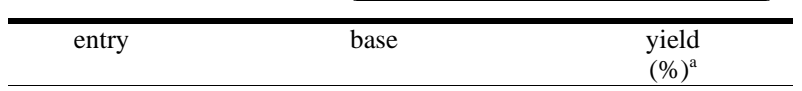

$$
\begin{aligned}
& \begin{array}{lcc}
1 & \text { NaOH (aq } 50 \% v / v) & 56 \\
2 & \text { KHMDS (solution in PhMe) } & 29 \\
3 & { }^{t} \text { BuOK } & 59 \\
4 & \mathrm{P}_{1} & 90 \\
5 & \mathrm{P}_{2}(t-\mathrm{Bu}) & 95
\end{array}
\end{aligned}
$$

${ }^{\text {a Determined by }}{ }^{1} \mathrm{H}$ NMR spectroscopy using an internal standard.

$50 \% \mathrm{NaOH}$ - which had proven useful in an earlier study $^{12}$ on the influence of hydrogen-bond donating catalysts on the CC reaction - gave moderate yields of $\mathbf{2}$ under our standard conditions (entry 1), while neither KHMDS nor $\mathrm{KO}^{\mathrm{t}} \mathrm{Bu}$ mediated the reaction to a synthetically useful degree (entries 2-3). Commercially

\footnotetext{
${ }^{12}$ Kavanagh, S. A.; Piccinini, A.; Connon, S. J. Org. Biomol. Chem.
} 2008, 6, 1339. available $\mathrm{P}_{1}$ and $\mathrm{P}_{2}$ phosphazene organic bases fared significantly better and led to the formation of $\mathbf{2}$ in excellent yield, with the $\mathrm{P}_{2}$ base $\mathrm{e}^{13}$ proving superior.

Scheme 3: Use of the sulfide at catalytic loadings

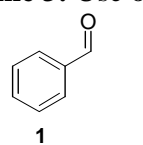

$$
\begin{gathered}
\stackrel{9}{\mathrm{MeOTf}(1.0 \text { equiv })} \\
\underset{\mathrm{CH}_{2} \mathrm{Cl}_{2}(0.315 \mathrm{M}), \mathrm{rt}}{\mathrm{base}(1.0 \text { equiv), } 20 \mathrm{~h}} \\
18 \% \text { (57\% convn) }
\end{gathered}
$$
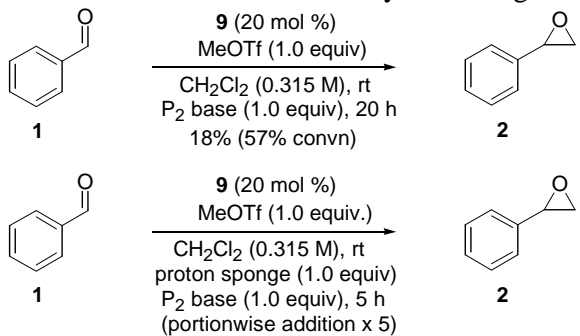

(portionwise addition $\times 5$ ) $95 \%$

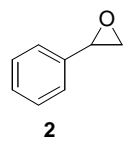

(average of 3 runs)

We were now ready to bring both efficient alkylation and deprotonation to bear on the methylene transfer process. Unfortunately treatment of $\mathbf{1}$ with stoichiometric amounts of MeOTf and $\mathrm{P}_{2}$ base in the presence of 20 mol\% of sulfide 9 resulted in poor product yield, despite considerable conversion of the aldehyde. Interestingly, we also noted the presence of phenylacetaldehyde (presumably a Meinwald rearangement ${ }^{14}$ product) in the crude ${ }^{1} \mathrm{H}$ NMR spectrum of these reactions. This led us to speculate that a) the alkylating agent is not compatible with the $\mathrm{P}_{2}$ base when both are present together in solution and b) a protic species in solution (possibly due to the presence of adventitious water) is capable of catalyzing the deleterious Meinwald rearrangement.

To circumvent these two difficulties we developed a modified protocol: use of proton sponge additive avoids the Meinwald rearrangement, while addition of the alkylating agent and base in 5 portions (with a ca. $20 \mathrm{~min}$ interval) allows the consumption of the methyl triflate to occur prior to introduction of each portion of base. While portion-wise addition is obviously less desirable than a protocol involving initial addition of all reagents, the excellent efficiency of both the individual alkylation and deprotonation steps and the liquid nature of both added reagents (i.e. they can be injected via syringe) results in a convenient and remarkably reproducible catalytic protocol which can be executed in 5 hours and furnished an average of $95 \%$ product yield over 3 experiments. ${ }^{15}$

Table 3. Evaluation of substrate scope

\footnotetext{
${ }^{13}$ Phosphazene bases have been previously used in stoichiometric CC reactions involving semistabilsed ylides, for examples see: (a) SolladiéCavallo, A.; Bouérat, L.; Roje, M. Tetrahedron Lett. 2000, 41, 7309. (b) Solladié-Cavallo, A.; Roje, M.; Isarno, T.; Sunjic, V.; Vinkovic V. Eur. J. Org. Chem. 2000, 1077. (c) Aggarwal, V. K.; Bae, I.; Lee, H. -Y.; Richardson, J.; Williams, D. T. Angew. Chem. Int. Ed. 2003, 42, 3274.

${ }^{14}$ Meinwald, J.; Labana, S. S.; Chadha, M. S. J. Am. Chem. Soc. 1963, 85, 582.

${ }^{15}$ A key predictor of success in these experiments is having prior knowledge of the interval required to ensure complete alkylation of 9 (20 mol\%) by MeOTf (20 mol\%) at the concentration to be used in the epoxidation protocol.
} 


aldehyde

${ }^{\mathrm{a}}$ Isolated yield. ${ }^{\mathrm{b}}$ Determined by ${ }^{1} \mathrm{H}$ NMR spectroscopy using an internal standard due to product decomposition during chromatography.

We were next interested in investigating the issue of substrate scope (Table 3). We were pleased to observe that under these conditions $\mathbf{9}$ could promote methylene transfer to $\mathbf{1}$ (at either 10 or $20 \mathrm{~mol} \%$ loadings, entries 12 ), together with a range of hindered- (entry 3), deactivated (entries 4-5) and activated (entries 6-7) aromatic aldehydes to afford epoxides 2 and 19-23 in excellent yields. $\alpha, \beta$-Unsaturated (entry 8) and $\alpha$ branched aliphatic aldehydes (16 and 17 respectively, entries 8-9) are also good substrates, although an unbranched aldehyde did not furnish epoxide 26, presumably due to competeitive homo-aldol reactions.

Finally, we then synthesized two novel chiral analogues of 9 (i.e. 27 and 28) with a view towards catalysis of an asymmetric CC reaction involving methylene transfer. Both materials proved capable of promoting the reaction efficiently; furnishing 2 in high yield. The isopropyl-substituted catalyst $\mathbf{2 7}$ provided the epoxide product with very modest levels of enantioselectivity, ${ }^{16}$ however use of the bulkier tert-butyl analogue 28 allowed the isolation of $(\boldsymbol{R})-2$ in $43 \%$ ee. While this is not on a par with the levels of selectivity achievable using semistabilized ylides, this methodology affords levels of product enantiomeric excess approaching those obtainable using the benchmark literature procedures for asymmetric methylene transfer, but requires 5-10 times less catalyst and provides the product in significantly higher yield (Schemes 1 and 4).

Scheme 4: Catalytic asymmetric methylene transfer
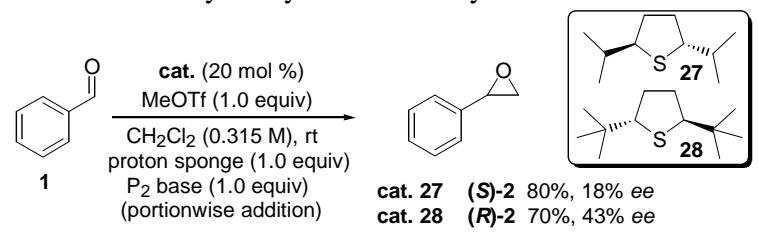

In summary, an investigation into the low catalyst activity in CC reactions involving methylene transfer resulted in the development of a methodology capable of converting aromatic, $\alpha, \beta$-unsaturated and aliphatic aldehydes to the corresponding terminal epoxides in excellent yields using $10-20 \mathrm{~mol} \%$ of a simple sulfide catalyst. An asymmetric variant of this process was also developed which could produce styrene oxide in up to $43 \%$ ee. This field (enantioselective methylene transfer to aldehydes) has been relatively dormant over the past 5 years. We would be optimistic that this protocol - the first not to require (super)stoichiometric amounts of chiral sulfide (prepared via multistep syntheses) will facilitate the development of new sulfide catalyst systems, the methylides derived from which could be better able to discriminate between aldehyde faces in the betaine-forming reaction step.

Acknowledgment This material was based on work funded by Science Foundation Ireland. We dedicate this work to the memory Paul B. Connon, an aspiring young scientist and our coworker in this endeavour who sadly passed away before submission of this manuscript.

Supporting Information Available General experimental procedures, ${ }^{1} \mathrm{H}$ and ${ }^{13} \mathrm{C}$ NMR spectra, characterisation data, HPLC assays. This material is available free of charge via the Internet at http://pubs.acs.org

\footnotetext{
${ }^{16}$ Enantioselectivity in these reactions is strongly dependent on the steric bulk of the sulfide substituents - for instance in an epoxidation experiment using a stoichiometric amount of the methyltriflate salt of a 2,5-dimethyl analogue of $\mathbf{2 7},(\boldsymbol{S})-2$ was isolated in $2 \%$ ee.
} 